\title{
INVENTARIANDO O CORPO NA PESQUISA EDUCACIONAL: sobre a constituição de um arquivo proliferante
}

\author{
Angélica Vier Munhoz \\ Universidade do Vale do Taquari - Univates \\ Julio Groppa Aquino \\ Universidade de São Paulo - USP
}

\begin{abstract}
Resumo
Este artigo apresenta alguns resultados de uma investigação acerca dos empregos da ideia de corpo na pesquisa educacional, tendo como suporte teórico-metodológico a noção de arquivo segundo Michel Foucault. Assim, foram selecionados os resumos de artigos - publicados no período de 1997 a 2018 - dos 55 periódicos da área educacional mais bem avaliados pela Coordenação de Aperfeiçoamento de Pessoal de Nível Superior (CAPES), de acordo com os estratos A1, A2 e B1 no último quadriênio avaliativo. A imersão no material selecionado demandou, inicialmente, a contextualização das principais reincidências discursivas, suas saturações e, ao mesmo tempo, suas reinvenções constantes. No segundo momento, optou-se por um procedimento de inventariação dos enunciados em circulação, a fim de situar os diferentes modos como a ideia de corpo subscreve e, outras vezes, extravasa os discursos dominantes na pesquisa educacional. Em síntese, operou-se um mosaico de distintas discursividades sobre o corpo na educação, apontando a impossibilidade de apreendê-lo segundo uma totalidade lógica.
\end{abstract}

Palavras-chave: corpo; arquivo; pesquisa educacional

\begin{abstract}
This article presents some results of an investigation about the uses of the idea of body in educational research, having as theoretical and methodological support the notion of archive according to Michel Foucault. Thus, the abstracts of the articles, published in the period from 1997 to 2018, of the 55 Brazilian educational journals better evaluated by the Coordination of Improvement of Higher Education Personnel (CAPES) were selected, according to the layers A1, A2 and B1 in the last evaluative quadrennium. The immersion in the selected material initially demanded the contextualization of the main discursive recurrences, their saturations and, at the same time, their constant reinventions. In the second moment, the procedure chosen was the inventorying of circulating statements in order to situate the different ways by which the idea of a body subscribes and, other times, goes beyond the dominant discourses in educational research. In summary, the discussions set a mosaic of distinct discourses on the body in education, pointing out the impossibility of grasping it in a logical whole.
\end{abstract}

Keywords: body; archive; educational research 
O presente artigo deriva de uma investigação acerca dos empregos da ideia de corpo na pesquisa educacional, tendo como suporte teórico-metodológico a noção de arquivo segundo Michel Foucault (2015, p. 158), para quem esta descreve

[...] a lei do que pode ser dito, o sistema que rege o aparecimento dos enunciados como acontecimentos singulares. Mas o arquivo é, também, o que faz com que todas as coisas ditas não se acumulem indefinidamente em uma massa amorfa, não se inscrevam, tampouco, em uma linearidade sem ruptura e não desapareçam ao simples acaso de acidentes externos.

Longe de consistir em um depósito estanque das representações ou das mentalidades correntes em determinada época, o arquivo, para Foucault, consiste no conjunto de regras que permite o aparecimento, a ativação e o apagamento de determinados mecanismos veridictivos, cujos ecos prolongam-se no presente. Na contramão de uma história linear obstinada em compilar/interpretar fatos supostamente paradigmáticos, Foucault (2008) compreende o arquivo como um conjunto articulado de discursividades que se desloca, se transforma e se atualiza de modo permanente. Instância de recriação de novos sentidos históricos, por meio da reativação das problematizações a eles subjacentes, o arquivo, na perspectiva adotada por Foucault, remete fundamentalmente a uma inquirição permanente do próprio presente e suas forças discursivas prevalentes sequiosas de naturalização.

O approach arquivístico descreve, assim, um “[...] pequeno gesto que consiste em deslocar o olhar, ele torna visível o que é visível, faz aparecer o que está tão próximo, tão intimamente ligado a nós que, por isso mesmo, não o vemos” (FOUCAULT, 2011, p. 246).

Em meio a tal perspectiva geral, partiu-se de uma seleção dos resumos de artigos de 55 periódicos da área educacional que constaram do sistema Qualis Periódicos da CAPES como A1, A2 e B1, segundo o último quadriênio avaliativo (2013-2016), os quais foram publicados no período de 1997 a 2018.

Cumpre informar que foram eleitas apenas as produções do campo educacional stricto sensu, uma vez que outras áreas de conhecimento têm alguns de seus periódicos contemplados ali. Ainda, tratou-se de privilegiar os periódicos que abarcavam concomitantemente diferentes subáreas do campo educacional, preterindo-se, portanto, as publicações de cunho mais temático (por exemplo, de história da educação ou de educação matemática, dentre outras).

A demarcação do período 1997-2018 baseou-se no advento da Lei de Diretrizes e Bases - LDB 9394/96, a qual entrou em vigor em 20 de dezembro de 1996, tomada aqui como marco histórico no que se refere não apenas às balizas legais do campo, mas sobretudo aos modos de pensamento aí em circulação.

A imersão no material selecionado voltou-se, inicialmente, ao arquivamento das aparições da ideia de corpo nos resumos, a partir dos descritores corpo, corporal e corporeidade. No segundo momento, o trabalho consistiu em um movimento de arquivização de tais achados. Arquivamento e arquivização constituem-se como dois procedimentos de um mesmo processo analítico, tal como afirmam Aquino e Val (2017, p. 48), para quem “[...] 
a obstinação documentária está para o primeiro procedimento [arquivamento] do mesmo modo que a imaginação recriadora está para o segundo [arquivização]”. Assim, se o arquivamento diz respeito à reorganização de fontes, a arquivização possibilita encontrar, em meio a tais fontes, a potência de sua recriação e revitalização. Dito de outro modo, tais gestos articulados possibilitam endereçar-se às produções discursivas atinentes ao tema sob escrutínio por meio da configuração das problematizações que facultaram a consecução e a reinvenção dos discursos sobre o corpo na pesquisa educacional brasileira.

O arquivamento efetuado sinaliza, em primeira instância, aquilo que, supõe-se, é conhecido de antemão: no discurso educacional, o corpo aparece de diferentes formas, por meio de diferentes agenciamentos. Mas como dar visibilidade a essa produção discursiva? Como arquivizá-la? O desafio que se impôs então foi o de inventar um modo de tratamento específico do material, apontando para a constituição de séries - estas compostas, sobretudo, de modulações e ondulações narrativas em torno do tema nas produções veiculadas nos periódicos da área -, sem, contudo, qualquer intenção de “[...] realizar interpretação dos textos selecionados, sem vasculhar por detrás ou além deles em busca de um sentido latente ou perdido, enfim, sem tentar legitimá-los ou os invalidar” (AQUINO; VAL, 2017, p. 47).

A escolha de um approach analítico desse timbre envolve um exercício de configuração das tensões discursivas aí em curso, o qual implica, por sua vez, a produção de novos sentidos àquilo com ali se deparou. Nessa perspectiva, tomamos os registros sobre o corpo e os reorganizamos segundo alguns tópicos: multiplicidade de temas; autores de referência; áreas de abrangência etc. O que interessa, aqui, é dar a ver as reincidências discursivas, suas saturações e, ao mesmo tempo, suas reinvenções constantes. Contudo, é preciso reconhecer que a tentativa diligente de classificação também mostra sua insuficiência, pois, ao buscar enquadrar o material arquivado segundo estas ou aquelas categorias, apercebe-se, de imediato, de que muitos elementos aí presentes revelam-se inclassificáveis.

Desta feita, buscou-se endereçar-se ao arquivo de diferentes maneiras, assim como criar estratégias para perfurá-lo, percorrendo seus movimentos, encontrando conexões, aproximando heterogêneos. Eis o primeiro movimento.

\section{Em torno de um arquivamento da ideia de corpo}

Da investida analítica primeira, destacamos os seguintes achados: no montante de 30.487 resumos constantes de 2.588 números (quadro I abaixo), foram rastreados 892 resumos referentes à noção de corpo e seus respectivos desdobramentos.

\begin{tabular}{|c|c|c|c|}
\hline Periódico & $\begin{array}{c}\text { Números } \\
\text { publicados }\end{array}$ & $\begin{array}{c}\text { Resumos } \\
\mathbf{( 1 9 9 7 - 2 0 1 8 )}\end{array}$ & $\begin{array}{c}\text { Resumos } \\
\text { relacionados ao } \\
\text { tema corpo }\end{array}$ \\
\hline Educação \& Sociedade & 88 & 1231 & 16 \\
\hline Educar em Revista & 73 & 1080 & 46 \\
\hline
\end{tabular}




\begin{tabular}{|c|c|c|c|}
\hline $\begin{array}{l}\text { Revista da FAEEBA - Educação e } \\
\text { contemporaneidade }\end{array}$ & 47 & 879 & 15 \\
\hline Pro-posições & 66 & 744 & 53 \\
\hline Educação e pesquisa & 66 & 807 & 20 \\
\hline Cadernos de pesquisa (FCC) & 68 & 799 & 14 \\
\hline Educação \& Realidade & 61 & 831 & 53 \\
\hline Educação Pública & 63 & 687 & 16 \\
\hline Educação PUCRS & 67 & 780 & 14 \\
\hline Revista Brasileira de Educação & 71 & 783 & 23 \\
\hline $\begin{array}{c}\text { Revista Ibero-Americana de estudos em } \\
\text { educação }\end{array}$ & 53 & 864 & 32 \\
\hline Revista Teias & 53 & 804 & 19 \\
\hline Revista Diálogo Educacional & 60 & 766 & 06 \\
\hline Educação em Revista & 56 & 794 & 24 \\
\hline ETD - Educação e Temática digital & 60 & 748 & 46 \\
\hline Perspectiva & 59 & 708 & 16 \\
\hline Revista Educação UFSM & 56 & 684 & 26 \\
\hline Comunicações & 51 & 636 & 26 \\
\hline $\begin{array}{c}\text { Revista Brasileira de Estudos } \\
\text { Pedagógicos }\end{array}$ & 53 & 608 & 07 \\
\hline Cadernos de Educação & 54 & 578 & 15 \\
\hline Reflexão e ação & 49 & 588 & 21 \\
\hline Série-Estudos & 46 & 538 & 02 \\
\hline Educação Unisinos & 50 & 560 & 11 \\
\hline Revista Espaço Pedagógico & 27 & 507 & 09 \\
\hline Linhas Críticas & 47 & 511 & 04 \\
\hline Inter-ação & 46 & 494 & 17 \\
\hline Revista Educação em Questão & 58 & 486 & 10 \\
\hline EccoS - Revista científica & 47 & 462 & 07 \\
\hline Atos de Pesquisa em Educação & 41 & 482 & 29 \\
\hline e-Curriculum & 51 & 515 & 15 \\
\hline Cadernos CEDES & 65 & 413 & 28 \\
\hline Educação em Foco (UFJF) & 47 & 482 & 15 \\
\hline Horizontes & 41 & 469 & 06 \\
\hline Revista de Educação PUC - Campinas & 48 & 459 & 06 \\
\hline
\end{tabular}




\begin{tabular}{|c|c|c|c|}
\hline Educação Teoria \& Prática & 41 & 404 & 14 \\
\hline Roteiro & 49 & 436 & 07 \\
\hline $\begin{array}{c}\text { Cadernos de Pesquisa: Pensamento } \\
\text { Educacional }\end{array}$ & 37 & 476 & 14 \\
\hline Linguagens, Educação e Sociedade & 12 & 440 & 16 \\
\hline $\begin{array}{c}\text { Revista Educação e Cultura } \\
\text { Contemporânea }\end{array}$ & 41 & 477 & 16 \\
\hline Currículo sem fronteiras & 44 & 434 & 22 \\
\hline Educação, Ciência e Cultura & 46 & 421 & 11 \\
\hline Revista Educativa - Revista de educação & 56 & 422 & 10 \\
\hline Em Aberto & 18 & 313 & 10 \\
\hline $\begin{array}{l}\text { Revista Eletrônica de Educação - } \\
\text { Reveduc } \\
\end{array}$ & 29 & 406 & 06 \\
\hline Revista Cocar & 23 & 387 & 26 \\
\hline Práxis Educacional & 28 & 366 & 05 \\
\hline Quaestio & 42 & 367 & 07 \\
\hline Revista Práxis Educativa & 30 & 364 & 06 \\
\hline Acta Scientiarum Education & 27 & 333 & 04 \\
\hline Tempos e Espaços em Educação & 28 & 386 & 36 \\
\hline Retratos da escola & 22 & 318 & 07 \\
\hline Educação em Foco (UEMG) & 35 & 304 & 02 \\
\hline Imagens da Educação & 24 & 217 & 05 \\
\hline Cadernos de pesquisa (UFMA) & 48 & 236 & 09 \\
\hline Educação em Perspectiva & 20 & 203 & 01 \\
\hline Total & 2.588 & 30.487 & 892 \\
\hline
\end{tabular}

\section{Multiplicidade dos temas correlatos}

O corpo incide sobre vários outros temas. O quadro abaixo (II) mostra o número de vezes em que, nos resumos selecionados, tais temas cruzam-se com o corpo. Cabe destacar que, mesmo que cada um desses unitermos possa ter aparecido diversas vezes no mesmo resumo, tal encontro foi registrado uma única vez.

A organização por grupos temáticos dá-se por aproximação semântica, não sendo, portanto, definitiva, uma vez que muitos conceitos/noções poderiam ser enquadrados em outros grupos. O que importa aqui não é a estabilidade das classificações, mas o processo heteróclito, em contínua atualização, que as caracteriza. 
Mesmo que haja uma tentativa de ordenar os achados em determinadas maneiras (grupos, listas, séries...), estas, por sua vez, tornam-se rapidamente disformes, na medida em que outros elementos se avizinham e findam por desarranjar as composições já organizadas.

\begin{tabular}{|c|c|c|c|c|c|}
\hline GRUPO 01 & $\mathbf{N}^{\mathbf{o}}$ & GRUPO 02 & $\mathbf{N}^{\mathbf{o}}$ & GRUPO 03 & $\mathbf{N}^{\circ}$ \\
\hline $\begin{array}{l}\text { Contemporaneidade } \\
\text { Modernidade } \\
\text { Pós-Modernidade }\end{array}$ & $\begin{array}{l}02 \\
07 \\
03\end{array}$ & $\begin{array}{c}\text { Cuidado/Cuidar } \\
\text { Morte } \\
\text { Saúde } \\
\text { Transtornos } \\
\text { Obesidade } \\
\text { Medicalização } \\
\end{array}$ & $\begin{array}{l}03 \\
04 \\
17 \\
02 \\
02 \\
02 \\
\end{array}$ & $\begin{array}{c}\text { Butô } \\
\text { Contact Improvisation } \\
\text { Dança de rua } \\
\text { Teoria ator-rede }\end{array}$ & $\begin{array}{l}02 \\
02 \\
03 \\
02\end{array}$ \\
\hline GRUPO 04 & $\mathbf{N}^{\mathbf{o}}$ & GRUPO 05 & $\mathbf{N}^{\mathbf{o}}$ & GRUPO 06 & $\mathbf{N}^{\mathbf{o}}$ \\
\hline $\begin{array}{l}\text { Autor/autoria } \\
\text { Cartografia } \\
\text { Escrita } \\
\text { Leitura } \\
\text { Narrativas }\end{array}$ & $\begin{array}{l}02 \\
09 \\
07 \\
04 \\
05\end{array}$ & $\begin{array}{c}\text { Bebês } \\
\text { Brincar } \\
\text { Cultura infantil } \\
\text { Infância } \\
\text { Jogo } \\
\text { Lúdico/ludicidade } \\
\end{array}$ & $\begin{array}{l}09 \\
07 \\
02 \\
52 \\
04 \\
04\end{array}$ & $\begin{array}{c}\text { Ciberespaço } \\
\text { Cultura digital } \\
\text { Juventude/adolescência } \\
\text { Mídia } \\
\text { Redes sociais } \\
\text { TICs } \\
\end{array}$ & $\begin{array}{l}01 \\
04 \\
24 \\
10 \\
02 \\
06\end{array}$ \\
\hline GRUPO 07 & $\mathbf{N}^{\mathbf{o}}$ & GRUPO 08 & $\mathbf{N}^{\mathbf{o}}$ & GRUPO 09 & $\mathbf{N}^{\mathbf{0}}$ \\
\hline $\begin{array}{c}\text { Direitos humanos } \\
\text { Ditadura } \\
\text { Movimentos sociais } \\
\text { Neoliberalismo } \\
\text { Políticas públicas } \\
\text { Resistência } \\
\text { Anarquismo }\end{array}$ & $\begin{array}{l}01 \\
02 \\
02 \\
02 \\
06 \\
02 \\
01\end{array}$ & $\begin{array}{c}\text { Educação sexual } \\
\text { Feminismo } \\
\text { Gênero } \\
\text { Homofobia } \\
\text { Homossexualidade } \\
\text { Masculinidade } \\
\text { Queer } \\
\text { Sexualidade } \\
\text { Diversidade sexual } \\
\text { Heteronormatividade }\end{array}$ & $\begin{array}{c}03 \\
12 \\
125 \\
03 \\
02 \\
11 \\
13 \\
56 \\
04 \\
03\end{array}$ & $\begin{array}{c}\text { Alteridade } \\
\text { Bullying } \\
\text { Deficiência } \\
\text { Diferença } \\
\text { Exclusão } \\
\text { Inclusão } \\
\text { Normalidade(zação) } \\
\text { Surdez }\end{array}$ & $\begin{array}{l}01 \\
03 \\
12 \\
13 \\
04 \\
11 \\
03 \\
08\end{array}$ \\
\hline GRUPO 10 & $\mathbf{N}^{\mathbf{o}}$ & GRUPO 11 & $\mathbf{N}^{\mathbf{o}}$ & GRUPO 12 & $\mathbf{N}^{\circ}$ \\
\hline $\begin{array}{c}\text { Carne } \\
\text { Castigos corporais/torturas } \\
\text { Cultura do corpo } \\
\text { Fitness } \\
\text { Movimento } \\
\text { Pedagogias/educação do } \\
\text { corpo } \\
\text { Performatividade } \\
\text { Práticas corporais } \\
\text { Imagem corporal }\end{array}$ & $\begin{array}{l}02 \\
04 \\
10 \\
06 \\
10 \\
\\
15 \\
05 \\
25 \\
04 \\
\end{array}$ & $\begin{array}{c}\text { Cultura } \\
\text { Diversidade } \\
\text { Eugenia } \\
\text { Identidade } \\
\text { Imigração } \\
\text { Indígena } \\
\text { Raça } \\
\text { Representação } \\
\text { Velhice/Terceira Idade }\end{array}$ & $\begin{array}{l}34 \\
10 \\
05 \\
14 \\
01 \\
07 \\
13 \\
14 \\
08\end{array}$ & $\begin{array}{c}\text { Consumo } \\
\text { Cidade } \\
\text { Drogas } \\
\text { Família } \\
\text { Lazer } \\
\text { Museus } \\
\text { Práticas culturais } \\
\text { Sociedade } \\
\text { Trabalho }\end{array}$ & $\begin{array}{l}02 \\
07 \\
01 \\
01 \\
02 \\
02 \\
10 \\
06 \\
12\end{array}$ \\
\hline GRUPO 13 & $\mathbf{N}^{\mathbf{o}}$ & GRUPO 14 & $\mathbf{N}^{\mathbf{o}}$ & GRUPO 15 & $\mathbf{N}^{\mathbf{0}}$ \\
\hline $\begin{array}{c}\text { Biopoder } \\
\text { Biopolítica } \\
\text { Disciplina } \\
\text { Discurso }\end{array}$ & $\begin{array}{l}10 \\
08 \\
21 \\
18\end{array}$ & $\begin{array}{c}\text { Aprendizagem/aprender } \\
\text { Aula } \\
\text { Avaliação } \\
\text { BNCC }\end{array}$ & $\begin{array}{l}28 \\
01 \\
02 \\
01\end{array}$ & $\begin{array}{c}\text { Afetos } \\
\text { Agenciamento } \\
\text { Autopoésis } \\
\text { Corpo sem órgãos }\end{array}$ & $\begin{array}{l}07 \\
01 \\
01 \\
03\end{array}$ \\
\hline
\end{tabular}




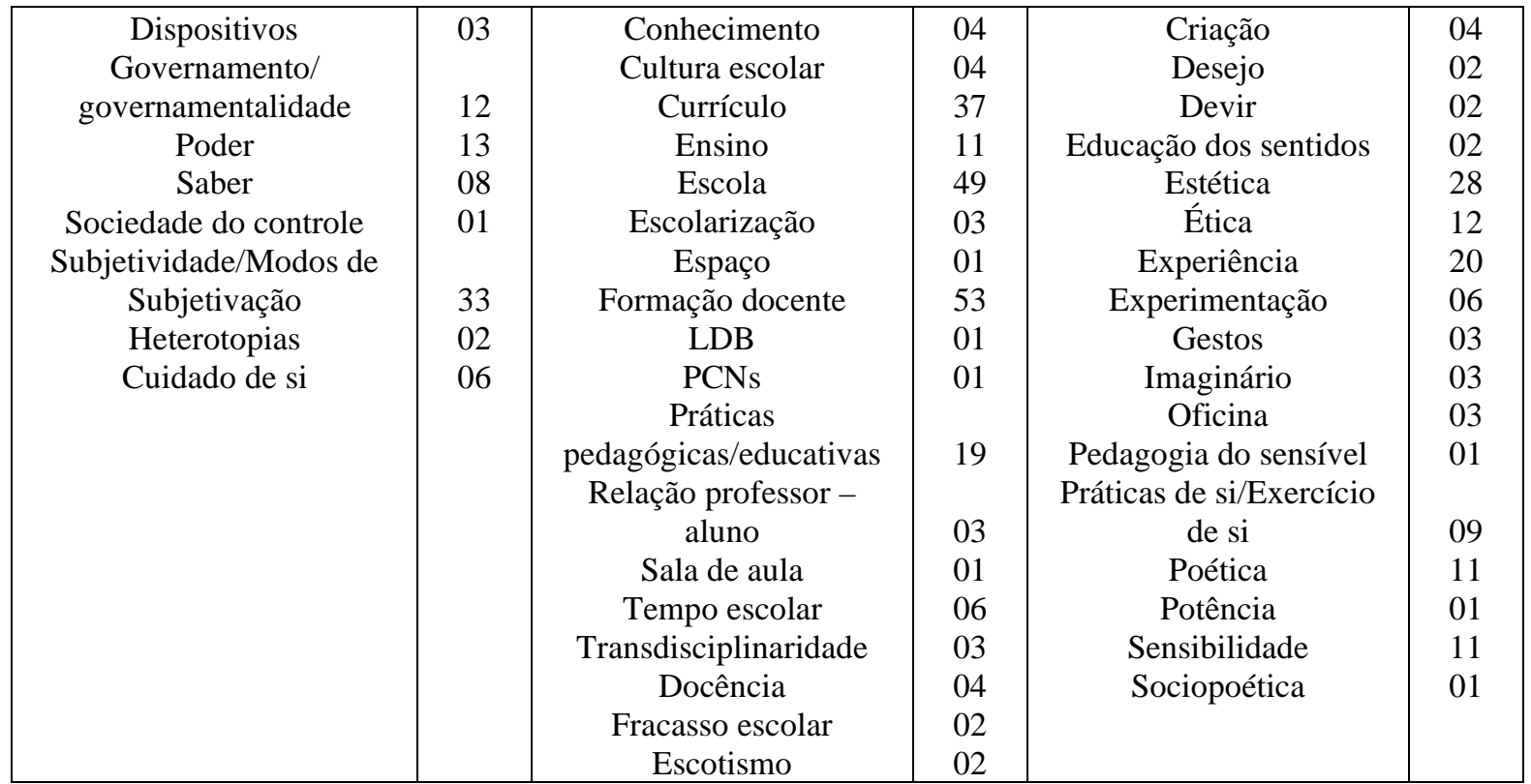

\section{Autores de referência}

Nesse ítem foram ordenados os autores de referência conforme seu aparecimento nos resumos selecionados, a partir do descritor corpo (e seus desdobramentos). Cabe destacar que somente foram classificados os autores de base, e não seus comentadores, embora houvesse muitos.

Certamente subclassificações poderiam ter sido criadas nessa categoria: autores clássicos e comentadores, autores brasileiros e estrangeiros, autores modernos e pós-modernos, autores homens e mulheres, autores por sua nacionalidade. No entanto, partimos apenas de uma classificação geral, no sentido de dar visibilidade às referências usuais que se encontram relacionadas ao tangenciamento do tema corpo no material investigado.

\begin{tabular}{|l|c|}
\hline \multicolumn{1}{|c|}{ Autor(es) } & $\begin{array}{c}\text { Número de vezes em } \\
\text { que é(são) citado(s) }\end{array}$ \\
\hline Michel Foucault & 59 \\
\hline Gilles Deleuze & 32 \\
\hline Theodor Adorno & 16 \\
\hline Maurice Merleau-Ponty & 14 \\
\hline Friedrich Nietzsche & 12 \\
\hline Pierre Bourdieu & 12 \\
\hline Gilles Deleuze e Félix Guattari & 08 \\
\hline
\end{tabular}




\begin{tabular}{|l|l|}
\hline Paulo Freire & 07 \\
\hline Baruch Spinoza & 06 \\
\hline Lev Vygotsky & 06 \\
\hline Jacques Lacan & 05 \\
\hline Max Horkheimer & 05 \\
\hline Gaston Bachelard & 04 \\
\hline Humberto Maturana & 04 \\
\hline Karl Marx & 04 \\
\hline Mikhail Bakhtin & 04 \\
\hline Sigmund Freud & 04 \\
\hline Jean Piaget & 03 \\
\hline Judith Butler & 03 \\
\hline Antonin Artaud & 02 \\
\hline Antônio Gramsci & 02 \\
\hline Georg W. F. Hegel & 02 \\
\hline Giorgio Agamben & 01 \\
\hline Hans Georg Gadamer & 02 \\
\hline Henry Wallon & 02 \\
\hline Jacques Rancière & 02 \\
\hline Jean-Jacques Rousseau & 02 \\
\hline Claude Lévi-Strauss & 02 \\
\hline Marcel Mauss & 02 \\
\hline Norbert Elias & 02 \\
\hline Paul Zumthor & 02 \\
\hline Peter Sloterdjik & 02 \\
\hline Platão & 02 \\
\hline Roland Barthes & 02 \\
\hline Walter Benjamin & 02 \\
\hline Zygmunt Bauman & 02 \\
\hline Anísio Teixeira & 02 \\
\hline Arthur Schopenhauer & 02 \\
\hline Alain Badiou & 02 \\
\hline Bertolt Brecht & 02 \\
\hline & 02 \\
\hline
\end{tabular}




\begin{tabular}{|c|c|}
\hline Boaventura de Souza Santos & 01 \\
\hline Claude Passeron & 01 \\
\hline Cornelius Castoradius & 01 \\
\hline Cristoph Türcke & 01 \\
\hline Donna Haraway & 01 \\
\hline Immanuel Kant & 01 \\
\hline Émile Jacques Dalcroze & 01 \\
\hline Emilia Ferreiro e Ana Teberosky & 01 \\
\hline Emmanuel Levinas & 01 \\
\hline François Dubet & 01 \\
\hline François Delsarte & 01 \\
\hline Georg Lukács & 01 \\
\hline Georges Didi-Huberman & 01 \\
\hline Georges Vigarello & 01 \\
\hline Gilbert Simondon & 01 \\
\hline Hannah Arendt & 01 \\
\hline Hélio Oiticica & 01 \\
\hline Henry Bergson & 01 \\
\hline Herbert Marcuse & 01 \\
\hline Howard Gardner & 01 \\
\hline Jacques Derrida & 01 \\
\hline Jacques-Paul Sartre & 01 \\
\hline Julia Kristeva & 01 \\
\hline Klaus Vianna & 01 \\
\hline Lygia Clark & 01 \\
\hline Matthew Lipman & 01 \\
\hline Max Stirner & 01 \\
\hline Max Weber & 01 \\
\hline Michel de Certeau & 01 \\
\hline Michel Mafessoli & 01 \\
\hline Nikolas Rose & 01 \\
\hline Paul Ricoeur & 01 \\
\hline Paul Valéry & 01 \\
\hline
\end{tabular}




\begin{tabular}{|l|l|}
\hline Jan Masschelein & 01 \\
\hline Pierre Lévy & 01 \\
\hline Pina Bausch & 01 \\
\hline René Descartes & 01 \\
\hline Rudolf Laban & 01 \\
\hline Samuel Beckett & 01 \\
\hline Serge Moscovici & 01 \\
\hline Sêneca & 01 \\
\hline Simone de Beauvoir & 01 \\
\hline Soren Kierkegaard & 01 \\
\hline Thomas Popkewitz & 01 \\
\hline
\end{tabular}

\section{Variações das abordagens}

O corpo também aparece em conexão com diferentes áreas de saber e/ou práticas. Muitas vezes elas figuram como uma espécie de gaveta na qual se coloca o que já se pensou, o que já se fez, o que já se falou. Mas elas também podem ter conexões múltiplas entre si, encontrar passagens, criar subcategorias.

\begin{tabular}{|l|c|}
\hline \multicolumn{1}{|c|}{ Área de saber / prática } & $\begin{array}{c}\text { Número de vezes em } \\
\text { que é citada }\end{array}$ \\
\hline Educação Física & 138 \\
\hline Educação (genericamente) & 67 \\
\hline Dança & 42 \\
\hline Linguagem & 21 \\
\hline Cinema & 16 \\
\hline Ciências (genericamente) & 16 \\
\hline Educação Ambiental & 16 \\
\hline Teatro & 14 \\
\hline Artes visuais & 14 \\
\hline História & 10 \\
\hline Pedagogia & 09 \\
\hline Filosofia & 06 \\
\hline Filosofia da Educação & 03 \\
\hline
\end{tabular}




\begin{tabular}{|l|l|}
\hline Música & 08 \\
\hline Fotografia & 07 \\
\hline Antropologia & 06 \\
\hline Performance & 06 \\
\hline Capoeira & 05 \\
\hline Literatura & 03 \\
\hline Matemática & 03 \\
\hline Yoga & 03 \\
\hline Libras & 03 \\
\hline Religião & 03 \\
\hline Geografia & 02 \\
\hline Biologia & 01 \\
\hline
\end{tabular}

\section{Níveis de Ensino}

Se tomarmos as classificações por níveis de ensino, temos a seguinte relação de combinações do corpo:

Educação Infantil - 44 vezes

Ensino Fundamental - 09 vezes

Ensino Superior - 06 vezes

Ensino Médio - 05 vezes

Educação do campo - 05 vezes

Educação Integral - 03 vezes

Educação Especial - 01 vez

\section{Correntes téoricas}

Quais teorias foram criadas acerca do corpo? Quantas teorizações tomam o corpo como objeto de estudo? Inúmeras, certamente. Muitas são evocadas nos resumos analisados. Se misturássemos autores com teorias, esses achados aumentariam significativamente e teríamos, por exemplo: Psicanálise x Freud $(9 \times 4)$ ou Psicanálise x Lacan $(9 \times 5)$. Dito de outro modo, os achados no arquivo organizam-se segundo certo perspectivismo, pois, dependendo das conjugações, os resultados se modificam - como se o que muda não fosse o que é dito, mas o mundo em que isso é dito, ou seja, a variação dá-se no âmbito da enunciação, não na do enunciado, lembrando mais uma vez Foucault (2015). 
Fenomenologia - 10 vezes

Estudos culturais -11 vezes

Psicanálise -09 vezes

Filosofia da diferença - 07 vezes

Sociologia da infância - 03 vezes

Psicomotricidade - 03 vezes

Hermenêutica - 03 vezes

Semiótica - 01 vez

\section{Entre o topos e o atopos}

Os dados acima elencados nos instam a prosseguir refletindo sobre o tipo de trabalho arquivístico aqui em pauta, uma vez que um arquivo pode se constituir como um topos, lugar “onde podem coexistir todos os saberes e referências sobre as coisas do mundo" (MACIEL, 2009, p. 66), mas também pode haver "uma profusão de arquivos espalhados em vários topoi” (MACIEL, 2009, p. 66). Para os gregos, o termo topos dizia respeito a lugar e discurso. "A palavra grega topos é, por um lado, o lugar onde se acha e acontece algo específico e por outro, os topoi são, desde Aristóteles, os pontos de vista gerais de uma fala a partir dos quais sentenças persuasivas podem ser seguidas” (TRAWNY, 2013, p. 7).

Para designar a refração ao enquadramento - o que não pode ser inserido em uma classe ou categoria, restando na ordem do inclassificável -, Roland Barthes (2003) se vale do termo atopos. Este sinaliza o desafio ao sistema de classificações, pois, mesmo passando por vários topoi, não se instala em nenhum. A atopia, adverte Barthes (2003, p. 33), "resiste à descrição, à definição, à linguagem, que é maia, classificação dos Nomes (das culpas)”. É desse modo que podemos pensar que as listas, catálogos, inventários e coleções compõem um processo, como afirma Vernant (apud Maciel, 2009, p. 28), nos quais os "arquivos de uma sociedade sem escrita, arquivos puramente lendários, não correspondem nem às exigências administrativas, nem a um desejo de glorificação real, nem a uma preocupação histórica”.

Também Umberto Eco (2010) aponta para a impossibilidade de tudo dizer ou descrever, referindo-se a Homero para designar o tópos da indizibilidade: "Frente a uma coisa imensa ou desconhecida, sobre a qual ainda não se sabe o suficiente ou não se saberá jamais, o autor nos diz que não é capaz de dizer e, diante disso, propõe um elenco abundante como amostra, deixando ao leitor a tarefa de imaginar o resto” (ECO, 2010, p. 49).

Mediante tal tarefa quimérica, optamos por um segundo procedimento de abordagem do material eleito: a inventariação. Por meio dela, operamos de modo a conjugar os achados anteriores sem partir de categorias já existentes, mas, ao contrário, intentando subverter a lógica dos sistemas estáveis de classificação. Nessa perspectiva, inventariar permite dar visibilidade não apenas às coisas já vistas, mas também à evidência da impossibilidade de mostrar tudo. Desse modo, o recurso da inventariação volta-se a elementos da ordem do inclassificável, ou seja, a classificações que não estão inseridas em categorias precisas, 
permitindo que sejam criados enquadramentos novos, incessantemente. Como pondera Maria Esther Maciel (2009, p. 15), “[...] se existe o inclassificável, é porque os sistemas de classificação disponíveis e legitimados são insuficientes e não dão conta de acomodar a complexa diversidade e multiplicidade do mundo”.

Para Foucault (2000, p. XVI), as classificações são "os códigos fundamentais de uma cultura - aqueles que regem sua linguagem, seus esquemas perceptivos, suas trocas, suas técnicas, seus valores, a hierarquia de suas práticas”. Assim, em face das classificações hierárquicas, os procedimentos de inventariação permitem novos agenciamentos, outras composições arquivísticas, de modo que o arquivo seja tratado como um "[...] lugar a ser explorado, um labirinto cujos caminhos estão em constante movimento, ativado intensamente pelas imagens que invadem e colorem as gavetas monocromáticas, desorganizando a ordem linear dos documentos e títulos” (PIMENTEL, 2014, p. 138). Assim, o gesto de inventariar desativa o arquivo como espaço de conservação, tornando "[...] seus elementos ativos para a invenção de um outro real possível” (PIMENTEL, 2014, p. 133).

Por outra perspectiva, a inventariação também poderia ser compreendida como uma arte do puzzle, tal como sugere Georges Perec (2009, p. 14):

[...] todo o gesto que faz o armador de puzzle, o construtor já o fez antes dele; toda peça que toma e retoma, examina, acaricia, toda combinação que tenta voltar a tentar, toda hesitação, toda intuição, toda esperança, todo esmorecimento foram decididos, calculados, estudados pelo outro.

Arte menor, mínima, segundo Perec, cuja incompletude denuncia a tentativa fracassada de controlar todas as possibilidades e combinações do mundo, a única coisa que conta, no domínio do puzzle, é a possibilidade de relacionar uma peça a outra, pois elas nada significam isoladamente: “o elemento não preexiste antes do conjunto, não é nem mais imediato, nem mais antigo; não são os elementos que determinam o conjunto, mas o conjunto que determina os elementos” (PEREC, 2009, p. 11). A infinidade de construção de tabelas e a conjugação de seus elementos são, para Perec, uma forma de ficcionalizar tal procedimento que, por isso mesmo, nunca se concretiza.

De nossa parte, temos que a tentativa de classificar e inventariar os achados sobre o corpo na pesquisa educacional transita entre um topos e um atopos, ou seja, entre lugares mais estáveis do discurso e outros que se encontram sempre abertos a novas composições. Na esteira de Eco (2010, p. 15), não se trata de um infinito potencial, no qual "[...] não se sabe quantas sãos as coisas das quais se fala”, mas um infinito atual "[...] feito de objetos talvez numeráveis, mas que nós não conseguimos enumerar - e tememos que sua numeração (e enumeração) não termine nunca” (ECO, 2010, p. 15). 


\section{Inventariações de inclassificáveis}

Em um pequeno fragmento do livro Classer/Penser, do mesmo Perec, intitulado Comment je classe?, o autor afirma: "meu problema com as classificações é que elas não duram; eu mal termino de colocar em ordem e esta ordem já está obsoleta” (PEREC, 2003, p. 163).

Pautados por essa espécie de lógica arquivística sempre inconclusa, agrupamos o que talvez fosse impossível ser classificado de modo ordenado, devido às suas particularidades e variações. Vale lembrar que o caráter desse tipo de ordenação é aleatório e, em certa medida, poético, uma vez que tantas outras ordenações poderiam ser criadas, de acordo com a imaginação daquele que se dispusesse a fazê-lo. Contudo, é importante destacar que as categorias inventariadas a seguir surgiram do interior do próprio arquivo ou, mais precisamente, foram produzidas com base nos afetos produzidos do encontro com ele.

Talvez tal categorização servisse para nos lembrar, mais uma vez, o que Umberto Eco (2010, p. 117) situa com precisão: “Os motivos por que se elaboram listas práticas parecem óbvios. Mas por que se fazem listas poéticas? [...] porque não somos capazes de enumerar alguma coisa que escapa às nossas capacidades de controle e denominação”.

\section{Razão e corpo}

Encontramos aqui uma crítica à cisão corpo-mente, ao corpo organizado, frente a uma posição clássica e dogmática do conhecimento, ou seja, o corpo tomado como um saber verdadeiro, como um organismo sensório-motor. Mas tal posição é sutil e controversa, pois, ao mesmo tempo em que há uma crítica a um pensamento dual cartesiano, há uma tentativa de definição do corpo como uma matéria estável e identitária: o corpo é, o corpo é, o corpo é.... Multiplica-se, assim, infinitamente os modelos de corpo a serem perseguidos.

\section{Delírios e insubordinações do corpo}

Corpo, corporeidade, corporalidade, corporificar, corporal, corpolatria, corpus. Corpos ciborgues. Corpos líquidos. Generificação do corpo. Poéticas do corpo. Corpo vibrátil. Corpo-escritura. Corpo-sensível. Gestos. Experiência estética. Corpo sem órgãos. Butô. Corpo biográfico. Prazeres do corpo. Escritas do corpo. Inscrições no corpo. Embodiment. Poesia do corpo. Corpo erótico. Potências da carne. Corpo-linguagem. Experimentações do corpo. Experimentações no corpo. Encontro do corpo com outros corpos. O que pode um corpo? Afetações do corpo. Sentidos do corpo. Práticas de si. Contact improvisation. Corpos em trânsito. Corpo presença. Fantasia idiorrítmica. Corpo sensação. Corpos em movimento. Performance art. Como dizer do indizível do corpo? 


\section{Somos o nosso corpo}

"Somos mãos, pés, boca, somos olhos, ouvidos, sexo; e porque os somos não os temos" (FERREIRA, 2011, p. 257). O corpo é ambíguo, porque se o somos é como se estivéssemos nele, mas se podemos perspectivá-lo também estamos fora dele. Busca-se falar a partir dele e não sobre ele. Pode-se falar dele, do corpo, o tempo todo, mas ele não está lá. Onde está o corpo? Aqui, ali, não, já em outro lugar. Entrelugar. Forma. Informe. Materialidade. Presença-ausência. Contornos. Em torno. Multiplicidades. Trascendência. No mundo. Serno-mundo. Corpo-sujeito. Corpo-vivido. Corpo-memória. Corpo no mundo. Meu corpo. Ser corpo. Sou corpo.

\section{Prefiro não}

Escrever, dizia Marguerite Duras, “também é não falar. É calar-se. É uivar sem ruído” (VILA-MATAS, 2004, p. 25). Sobre o corpo, talvez, fale-se demais. Escreve-se em demasia. Teoriza-se obstinadamente. Humanizar o corpo? Não, melhor emancipá-lo. Incluí-lo. Educálo. Performativizá-lo. Movimentá-lo. Subjetivá-lo. Medicalizá-lo. Quanto agenciamentos para o corpo? Diante do excesso, melhor, talvez, habitar a indeterminação do corpo, de modo a preservar sua potência infinita de recomposição.

\section{Educação do corpo}

Grades curriculares, métodos, disciplinas, avaliação. Espaços segmentados, empregos do tempo, hierarquização do saber, obediência, vigilância, torturas. Dociliza-se o corpo. Não há liberdade mínima para que possa haver um jogo de poder. "O lugar de estudo era isso. Os alunos se imobilizavam nos bancos: cinco horas de suplício, uma crucificação. Certo dia vi moscas na cara de um, roendo o canto do olho, entrando no olho. E o olho sem se mexer, como se o menino estivesse morto". (RAMOS, 2003, p. 206). Cultura fitness, práticas de saúde, escolhas sexuais, prolongamento da vida, internet, mídia, educação à distância. Burnout. Depressão. Yes, I can. Exaustão do corpo.

\section{Et cetera}

Umberto Eco (2010, p. 7) lembra que já em Homero se oscilava entre uma poética do "tudo está aqui” e uma do "et cetera”. Jorge Luis Borges (2007), no texto O idioma analítico de John Wilkins, cita uma enciclopédia chinesa intitulada Empório celestial de conhecimentos benévolos, a qual divide os animais em categorias inclassificáveis, em meio às quais uma das categorias chama-se et cetera. $\mathrm{O}$ artista Ricardo Basbaum, na $30^{\mathrm{a}}$ Bienal do Mercosul, cria a categoria artista etc. para designar um artista que não é só artista-artista, mas que também questiona o papel de artista.

Diante da impossibilidade de classificar todos os achados sobre corpo, et cetera pode dar forma a tudo aquilo para o que não há nome designativo, ou, de outro modo, o que poderia 
estar presente em qualquer designação. Et cetera, então, encarna a multiplicidade de elementos, mas poderia ser também um tudo vale, no sentido de poder pertencer a qualquer categoria. Entenda-se aqui, também, uma necessária infidelidade que faz com que um texto circule de um autor a outro, de uma teoria a outra, usurpando o original. Em suma, o et cetera talvez apenas afirme os limites que nos obrigam a compreender que sempre sobram restos, não importa o quê.

\section{Para além dos limites do corpo: variações}

“Que corpo? Temos muitos”, disse Roland Barthes (2006, p. 24) certa feita. Tal afirmação aponta para a ideia de que não há um corpo universal, centrado, unitário, predestinado aos discursos da ciência. Não há uma verdade do corpo, mas um mosaico de corpos atravessados pela história.

Para o filósofo Jean-Luc Nancy (1992), cada corpo é um caso particular no próprio sentido jurídico do termo. Assim, a cada corpo corresponderia uma espécie de jurisdição, de modo que a realidade do corpo seria a de "[...] uma materialidade protéica mas singularizante, de uma historicidade anônima, mas inventiva, sempre lutando contra a dominação de abstração e do universal” (SFORZINI, 2014, p.9)

Ao perguntar o que é o corpo, Foucault (2013) responde de pronto: é lugar. Assim, o seu texto O corpo utópico já de início honra seu título: "Meu corpo é o contrário de uma utopia, é o que jamais se encontra sob outro céu, lugar absoluto, pequeno fragmento de espaço com o qual, no sentido estrito, faço corpo" (FOUCAULT, 2013, p. 7). Foucault afirma tal ideia para lembrar que o corpo está aqui, nunca em outro lugar ou em lugar nenhum: "Meu corpo, topia implacável” (FOUCAULT, 2013, p. 8). Contudo, o pensador, em seguida, desconstrói essa tese ao defender que o corpo é um lugar utópico, um não lugar, um corpo sem corpo, um corpo incorpóreo ou uma pura potência que pode ser aniquilada: "Meu corpo está, de fato, sempre em outro lugar, ligado a todos os lugares do mundo e, na verdade, está em outro lugar que não o mundo" (FOUCAULT, 2013, p. 14).

O que Foucault parece vislumbrar é que o corpo pode habitar lugares sem lugar, reinventando-os, abrindo horizontes desde o lugar em que se está. O corpo, portanto, pode ser lugar da diferença, do devir, da experimentação, das heterotopias breves. Um lugar de fora no lugar de dentro. Um entre-lugares, portanto. Talvez tal gesto tenha a ver com uma pergunta proposta por Sloterdijk (2016, p. 29): “Onde estamos quando estamos no mundo?”

Quantos corpos aparecem na literatura educacional? Há muitas diferenças no que diz respeito aos entendimentos, representações, discursividades e modos de descrição do corpo, que vão desde um corpo cartesiano até a um corpo vivo, não orgânico, tal como aquele proposto por Antonin Artaud.

Por outra via, pode-se evidenciar, nos achados, que há sempre um continuum entre o corpus teórico e as experiências corpóreas, isso porque o modo como um corpo é descrito e analisado não está separado do seu modo de inscrição no mundo. 
Além disso, teorizar sobre o corpo também é uma experiência corpórea, de modo que os discursos sobre o corpo se misturam com os discursos do/no corpo. Assim, os discursos sobre o corpo do aluno, do doente, da criança, da mulher, os discursos feministas, psicanalíticos, filosóficos, sistêmicos, os discursos sobre a sexualidade e sobre a (a)normalidade, são por um lado disciplinares, segmentáveis, mas por outro se deslocam para um lugar de opacidade, na medida em que se aproximam de um horizonte histórico-político e carregam consigo a materialidade corpórea de um conjunto de forças coletivas.

Essa questão do corpo abriu um campo imenso através do qual tudo está ligado a tudo, uma vasta tessitura de problemas a partir do qual questiono se não há um estatuto especial da vida que corresponda a esse corpo; e também que tipo de tempo, que tipo de agenciamento de forças diferentes essa vida abre ao revelar um campo político ou social ainda a ser descoberto (UNO, 2014, p. 15).

É fato que o século XX tornou-se palco de pesquisas sobre o corpo e vários campos do saber debruçaram-se sobre as práticas do corpo, sobre os primados das neurociências, sobre a relação do corpo com a arte etc. Não parece ser por acaso que, nas últimas décadas, o corpo passou a ocupar lugar de destaque nos discursos das mais diversas áreas do saber, de modo que deve-se fazer o corpo falar, explorá-lo em seus aspectos mais íntimos, transformá-lo em matéria, torná-lo objeto de intervenção dos efeitos midiáticos, efetivá-lo como lugar de ação dos biopoderes, com vistas a otimizar a vida.

Talvez nunca tantos filósofos e pensadores acerca do corpo tenham sido lidos, citados e relidos, como é o caso de Foucault que aparece tantas vezes nos resumos da literatura educacional. Contudo, a incidência e a diversidade das discursividades sobre o corpo também nos mostra que, se é no corpo que tudo se passa, pois ele "é uma realidade bio-política" (FOUCAULT, 1979, p. 80), é impossível apreender discursivamente o corpo em uma totalidade lógica. Portanto, mais do procurar uma verdade única sobre o corpo, talvez seja necessário pensar “como a verdade toma corpo no corpo” (SFORZINI, 2014, p. 9).

Voltamos à Foucault para pensar que o corpo é um lugar utópico, para a qual criamos um projeto de saberes, práticas, instituições, um mercado que busca capturar, explicar, nomear e governar. Mas, pois por mais que tentemos capturá-lo e governá-lo, ele sempre nos escapa e nunca se realiza do modo como o idealizamos. O corpo produz heterotopias incessantemente, esses lugares inquietantes, imprevisíveis, que explodem os limites dos espaços dados, transfigurando suas conexões com o mundo, produzindo espaços outros e nos possibilitando pensá-lo de outros modos.

\section{Consideração finais}

Foucault (2001) denuncia o temor que as sociedades possuem em relação ao incontrolável do discurso, ao que resiste à ordenação, a tudo aquilo que possa colocá-lo em risco e, assim, abrir espaço para a proliferação de suas formas, “[...] de tudo o que nele pode 
haver de violento, de descontínuo, de combativo, de desordem, também, e de perigoso, desse grande zumbido incessante e desordenado do discurso” (FOUCAULT, 2001, p. 50).

Quando se trata de um arquivo e, nesse caso, um arquivo sobre o corpo, menos interessa o sujeito da enunciação, ou seja, aquele que discursa, mas aquilo que da própria discursividade emerge. Mais do que isso, interessa problematizar o que mais pode ser dito, atualizado, conjugado e, inevitavelmente, dispersado. Não necessariamente como acréscimos e acumulações, mas como uma espécie de esvaziamento da regularidade, dos resultados, dos territórios codificados, pois, como relembra Foucault (2001, p. 49), “o discurso nada mais é do que a reverberação de uma verdade nascendo diante de seus próprios olhos”.

Arquivar, classificar, arquivizar e inventariar as discursividades acerca do corpo consistiram no norte deste trabalho. As classificações e inventariações efetuadas foram uma tentativa, sem nenhuma pretensão de resultados estáveis, de demonstrar os diferentes modos como o corpo subscreve e, outras vezes, extravasa os discursos dominantes na pesquisa educacional, até mesmo porque "o enunciado é inseparável de uma variação inerente pela qual nunca estamos em um sistema, jamais paramos de passar de um sistema ao outro" (DELEUZE, 2005, p.17). Nessa perspectiva, outros arranjos analíticos com o arquivo em pauta fazem-se possíveis, tratando-se, afinal, da própria vitalidade do que aí se abriga e pede passagem.

\section{Referências}

AQUINO, Julio Groppa; VAL, Gisela Maria do. Uma ideia de arquivo: contributos para a pesquisa educacional. Pedagogía y Saberes, Bogotá, n. 49, p. 41-53, 2018.

BARTHES, Roland. O prazer do texto. Tradução J. Ginsburg. São Paulo: Perspectiva, 2006.

BARTHES, Roland. Fragmentos de um discurso amoroso. Tradução Márcia V. M. de Aguiar. São Paulo: Martins Fontes, 2003.

BORGES, Jorge Luis. Outras inquisições. Tradução Davi Arrigucci Jr. São Paulo: Companhia das Letras, 2007. DELEUZE, Gilles. Foucault. Tradução Claudia Sant’Anna Martins. São Paulo: Brasiliense, 2005.

ECO, Umberto. A vertigem das listas. Tradução Eliana Aguiar. Rio de Janeiro: Record, 2010.

FERREIRA, Vergílio. Invocação ao meu corpo. Lisboa: Quetzal Editores, 2011.

FOUCAULT, Michel. Arqueologia do saber. Tradução Luiz F. B. Neves. Rio de Janeiro: Forense Universitária, 2015.

FOUCAULT, Michel. O corpo utópico, as heterotopias. Tradução Salma Tannus Muchail. São Paulo: n-1, 2013.

FOUCAULT, Michel. A cena da filosofia. In: FOUCAULT, Michel. Arte, epistemologia,

filosofia e história da medicina. Rio de Janeiro: Forense Universitária, 2011a. p. 222-247.

FOUCAULT, Michel. A ordem do discurso. Tradução Laura Fraga de Almeida Sampaio. São Paulo: Edições Loyola, 2001.

FOUCAULT, Michel. As palavras e as coisas. Tradução Salma Tannus Muchail. São Paulo: Martins Fontes, 2000.

FOUCAULT, Michel. Microfísica do poder. Tradução Roberto Machado. Rio de Janeiro: Graal, 1979. 
MACIEL, Maria Esther. As ironias da ordem: coleções, inventários e enciclopédias ficcionais. Belo Horizonte: Editora UFMG, 2009.

NANCY, Jean-Luc. Corpus. Paris: Editions Métailié, 1992.

PEREC, Georges. A vida modos de usar. Tradução Ivo Barroso. São Paulo: Companhia

das Letras, 2009.

PEREC, Georges. Penser/Classer. Paris: Éditions du Seuil, 2003.

PIMENTEL, Leandro. O inventário como tática: a fotografia e a poética das coleções. Rio de Janeiro: Contracapa, 2014.

RAMOS, Graciliano. Infância. Rio de Janeiro: Editora Record, 2003.

SFORZINI, Arianna. Michel Foucault: une pensée du corps. Paris: Presses Universitaire de France, 2014.

SLOTERDIJK, Peter. Esferas I: bolhas. Tradução José Oscar de Almeida Marques. São Paulo: Estação Liberdade, 2016.

TRAWNI, Peter. Adyton: a filosofia esotérica de Heiddeger. Tradução Marcia Sá Cavalcanti Schuback. Rio de Janeiro: Mauad X, 2013.

UNO, Kuniichi. A gênese de um corpo desconhecido. Tradução Christine Greiner. São Paulo: n-1, 2014.

VILA-MATAS, Enrique. Bartebly e companhia. Tradução Maria Carolina de Araújo e Josely Vianna Baptista. São Paulo: Cosac Naify, 2004.

\section{Correspondência}

Angélica Vier Munhoz: Doutora em Educação; Docente da Universidade do Vale do Taquari (Univates).

E-mail: angelicavmunhoz@gmail.com

Julio Groppa Aquino: Doutor em Educação; Docente da Universidade de São Paulo (USP); Pesquisador produtividade CNPq.

E-mail: groppaq@usp.br

Texto publicado em Currículo sem Fronteiras com autorização dos autores 